\title{
ULTRASOUND EVALUATION OF NONTHYROIDAL NECK MASSES
}

\author{
Sudha Bindu Tirumani ${ }^{1}$, Vijaya Kumari Mudunoor ${ }^{3}$, Raghavendra Prasad Y3, Suman Chandra Aemjal ${ }^{4}$ \\ ${ }^{1}$ Assistant Professor, Department of Radiodiagnosis, Osmania General Hospital, Afzal Gunj, Hyderabad. \\ ${ }^{2}$ Associate Professor, Department of Radiodiagnosis, Osmania General Hospital, Afzal Gunj, Hyderabad. \\ ${ }^{3}$ Postgraduate, Department of Radiodiagnosis, Osmania General Hospital, Afzal Gunj, Hyderabad. \\ ${ }^{4}$ Professor, Department of Radiodiagnosis, Osmania General Hospital, Afzal Gunj, Hyderabad.
}

\section{ABSTRACT}

Ultrasound evaluation of neck masses is a noninvasive method with good diagnostic accuracy. A proper knowledge of anatomy of neck with confident anatomical localisation of the masses and the understanding of ultrasound features of each disease entity can help in the diagnosis and at times narrow the differential diagnosis of the various neck masses.

\section{AIMS AND OBJECTIVES}

To document and study the role of ultrasound in patients with nonthyroidal neck masses. To evaluate the various neck masses and differentiate benign and malignant masses based on their sonomorphology and correlate these with histopathology.

\section{MATERIALS AND METHODS}

In our study, during a period of 2 yrs. (May 2013 to April 2015) 56 patients admitted in the General Surgery and E.N.T. wards with neck masses other than thyroidal masses were evaluated with ultrasound examination of neck. Our study included patients of age groups 6 months to 67 years with 37 male and 19 female patients. High resolution ultrasound examination of neck was done by 7.5 MHz linear array transducer on Esaote MyLab Classic C.

\section{OBSERVATIONS AND RESULTS}

Out of 56 pts., the most common age of presentation was 21-40 yrs. There were 37 male and 19 female patients. All the 56 patients had neck masses and the common associated symptom was pressure effect due to the mass. On ultrasound, the nature of lesions ranged from solid, cystic to mixed (25). Most of the cases were unilateral neck masses. Out of 56 cases, solitary neck masses (31) were predominant. In this study, the most common neck mass was metastatic lymphadenopathy. The anatomic location and known ultrasound features of the various masses was very helpful in the diagnosis of these lesions.

\section{CONCLUSION}

Ultrasound is a safe noninvasive modality in the diagnosis of neck masses with good diagnostic accuracy.

\section{KEYWORDS}

Neck Masses, Ultrasound, Lymphadenopathy.

HOW TO CITE THIS ARTICLE: Tirumani SB, Mudunoor VK, Prasad RY, et al. Ultrasound evaluation of nonthyroidal neck masses. J. Evolution Med. Dent. Sci. 2016;5(63):4437-4442, DOI: 10.14260/jemds/2016/1013

\section{INTRODUCTION}

The diagnosis of neck masses has long been a challenge to radiologists. Many small, but critical structures pass from the head to the thorax through a region that is compact, yet remarkably flexible. A thorough understanding of the gross anatomy of the neck is needed to communicate findings precisely and generate meaningful differential diagnosis ${ }^{1}$. High resolution B-mode sonography has improved and has become a very valuable tool in the diagnosis of neck masses. Sonography is commonly the first imaging modality after clinical examination. It is cost effective procedure. It provides valuable diagnostic information with high degree of diagnostic accuracy. It is preferred to guide needle aspirations of all types of lesions of neck. The noninvasiveness of ultrasound makes this an ideal modality for evaluating neck masses in children and infants ${ }^{2}$.

Financial or Other, Competing Interest: None.

Submission 05-02-2016, Peer Review 30-05-2016,

Acceptance 04-06-2016, Published 06-08-2016.

Corresponding Author:

Raghavendra Prasad,

Room No. 222, PG Hostel,

Osmania General Hospital,

Hyderabad-500012.

E-mail: dr.raghavan08@gmail.com

DOI: $10.14260 /$ jemds/2016/1013
On the basis of sonographic findings, selection of additional imaging modalities including CT and MR can be applied more judiciously. CT and MRI provide essential information about deep extensions of neck masses and may delineate additional clinically unsuspected lesions.

\section{AIM OF THE STUDY}

1. To document and study the role of ultrasound in patients with nonthyroidal neck masses.

2. To evaluate the various neck masses and differentiate benign and malignant masses based on their sonomorphology.

3. To correlate the ultrasound findings with FNAC and/or histopathology.

4. To correlate the sonographic findings with additional imaging modalities like CT and MRI.

\section{MATERIALS AND METHODS}

In this institutional review board approved study, after informed consent, 56 patients admitted in the General Surgery and E.N.T. wards with nonthyroidal neck masses were evaluated with ultrasound examination of neck during a period of 2 yrs. (May 2013 to April 2015). Our study included patients of age groups 6 months to 67 years with 37 male and 
19 female patients. Patients were initially evaluated with routine investigations. Some patients were sent for radiographs of neck both $\mathrm{AP}$ and lateral views. High resolution ultrasound examination of neck was done by $7.5 \mathrm{MHz}$ linear array transducer on Esaote MyLab Classic C.

On ultrasound examination, the patients were thoroughly examined to localise the mass and confirm the nature of mass, either solid, cystic, or mixed. The size, shape of the lesion, and its relation to adjacent structures noted. Note of normal structures and any other non-palpable lesions is done. Presence of calcification, areas of necrosis in solid lesions, and any septations or debris or solid areas in cystic lesions is documented. All 56 patients underwent FNAC/excision biopsy. The findings of ultrasound were compared with FNAC/histopathology. Further evaluation with other investigations was done in 10 patients (CT and MRI) and findings of these investigations were recorded.

\section{TECHNIQUE OF ULTRASOUND EXAMINATION}

Pt. examined in supine position with neck mildly hyperextended. Neck examine with a high frequency linear array transducer ranging from 7.5 to $10 \mathrm{MHz}$. It begins with the examination of thyroid gland where the instrument is adjusted and frequency and gain are optimised. Depending on the indication, particular attention should be given to certain regions of neck. Level I evaluated in coronal plane and level II$\mathrm{V}$ evaluated longitudinally and in axial plane ${ }^{3}$.

Thyroid should be imaged entirely in both transverse and longitudinal planes. Potential enlargement of parathyroid glands must be evaluated. Parotid glands examined in axial plane. Enlarged L.N. should be looked for in all regions and if present measured in axial plane (Minimal axial diameter) ${ }^{4}$

\section{RESULTS}

\begin{tabular}{|c|c|c|}
\hline Sl. No. & Age Group & No. of Patients \\
\hline 1 & $<1$ year & 01 \\
\hline 2 & $01-20$ & 12 \\
\hline 3 & $21-40$ & 22 \\
\hline 4 & $41-60$ & 14 \\
\hline 5 & $61-80$ & 17 \\
\hline \multicolumn{2}{|c|}{ Total } & $\mathbf{5 6}$ \\
\hline \multicolumn{2}{|c|}{ Table 1: Age Incidence } \\
\hline
\end{tabular}

Out of 56 patients, most common age group was 21-40 yrs. and next common age group was $61-80$ year old. One patient was from $<1$ year age group.

\begin{tabular}{|c|c|c|}
\hline Sl. No. & Sex & No. of Patients \\
\hline 1 & Male & 37 \\
\hline 2 & Female & 19 \\
\hline \multicolumn{3}{|c|}{ Total } \\
\hline
\end{tabular}
female.

In our study, 37 patients were male and 19 patients were

\begin{tabular}{|c|c|c|}
\hline $\begin{array}{c}\text { Sl. } \\
\text { No. }\end{array}$ & Symptoms & $\begin{array}{c}\text { No. of } \\
\text { Patients }\end{array}$ \\
\hline 1 & Pain & 6 \\
\hline 2 & Fever & 4 \\
\hline 3 & Pressure symptoms & 7 \\
\hline \multicolumn{2}{|c|}{ dysple 3: Clinical Symptoms } \\
\hline
\end{tabular}

All 56 patients had swelling in the neck and the most common associated symptom was pressure effect due to the neck swelling.

\begin{tabular}{|c|c|c|}
\hline Sl. No. & Site of Swelling & No. of Patients \\
\hline 1 & Mid line & 4 \\
\hline 2 & Lateral & 52 \\
\hline \multicolumn{2}{|c|}{ Total } & $\mathbf{5 6}$ \\
\hline \multicolumn{2}{|c|}{ Table 4: Site of Swelling } \\
\hline
\end{tabular}

Most of the patients (52) had lateral neck masses and out of 4 midline masses and had thyroglossal duct cysts.

\begin{tabular}{|c|c|c|}
\hline $\begin{array}{c}\text { Sl. } \\
\text { No. }\end{array}$ & Site Involved & $\begin{array}{c}\text { No. of } \\
\text { Patients }\end{array}$ \\
\hline 1 & $\begin{array}{c}\text { Primary head and neck } \\
\text { carcinoma }\end{array}$ & 10 \\
\hline 2 & Non-head and neck carcinoma & 3 \\
\hline 3 & As a part of diffuse disease & 7 \\
\hline \multicolumn{2}{|c|}{ Total } & $\mathbf{2 0}$ \\
\hline \multicolumn{2}{|c|}{ Table 5: Involvement of Other Sites in the Body } \\
\hline
\end{tabular}

Neck masses secondary to head and neck carcinoma ${ }^{5}$ was seen in 10 patients and 3 patients ( 1 ca. stomach, 1 ca. bronchus, and $1 \mathrm{ca}$. testis) presented with left supraclavicular neck masses. 7 patients had neck masses as a part of diffuse disease. Out of this, 4 patients had lymphoma, 2 patients had tuberculosis, and 1 patient had cystic hygroma of the neck extending into the axilla.

\begin{tabular}{|c|c|c|}
\hline $\begin{array}{c}\text { Sl. } \\
\text { No. }\end{array}$ & X-ray Findings & $\begin{array}{c}\text { No. of } \\
\text { Patients }\end{array}$ \\
\hline 1 & Calcification & 4 \\
\hline 2 & Tracheal compression and \\
displacement & 4 \\
\hline \multicolumn{2}{|c|}{ Table 6: X-Ray Findings } \\
\hline
\end{tabular}

8 patients had x-ray neck, both AP and lateral views. 4 patients had calcification and 4 patients had tracheal compression and displacement.

\begin{tabular}{|c|c|c|}
\hline Sl. No. & Nature of the Lesion & No. of Patients \\
\hline 1 & Solid & 18 \\
\hline 2 & Cystic & 13 \\
\hline 3 & Mixed & 25 \\
\hline \multicolumn{2}{|c|}{ Total } & $\mathbf{5 6}$ \\
\hline \multicolumn{2}{|c|}{ Table 7: Ultrasound Findings } \\
\hline
\end{tabular}

\begin{tabular}{|c|c|c|}
\hline Sl. No. & Site of the Lesion & No. of Patients \\
\hline 1 & Unilateral & 44 \\
\hline 2 & Bilateral & 9 \\
\hline 3 & Midline & 4 \\
\hline \multicolumn{2}{|c|}{ Total } & $\mathbf{5 6}$ \\
\hline \multicolumn{2}{|c|}{ Table 8} \\
\hline
\end{tabular}

Predominantly, most of the neck masses were unilateral (44) and only 9 were bilateral neck lesions.

\begin{tabular}{|c|c|c|}
\hline Sl. No. & Number of Lesions & No. of Patients \\
\hline 1 & Solitary & 31 \\
\hline 2 & Multiple & 25 \\
\hline \multicolumn{2}{|c|}{ Total } & $\mathbf{5 6}$ \\
\hline & \multicolumn{2}{|c|}{ Table 9 } \\
\hline
\end{tabular}


31 patients had solitary neck lesions whereas 25 had multiple lesions.

\begin{tabular}{|c|c|c|}
\hline Sl. No. & Type of Lesion & No. of Patients \\
\hline 1 & Thyroglossal duct cyst ${ }^{6}$ & 3 \\
\hline 2 & Branchial cleft cyst $^{7}$ & 4 \\
\hline 3 & Lymphangioma 8,9 & 10 \\
\hline 4 & Abscess & 4 \\
\hline 5 & Tuberculous lymph nodes & 10 \\
\hline 6 & Salivary gland tumour & 3 \\
\hline 7 & Lymphoma & 4 \\
\hline 8 & Metastases & 18 \\
\hline & Total & 56 \\
\hline
\end{tabular}

Most common neck masses were metastases seen in 18 patients. Next most common lesion was tuberculosis and lymphangioma.

\begin{tabular}{|c|c|c|}
\hline Sl. No. & Type of Lesion & No. of patients \\
\hline 1 & Nonspecific lymphadenitis & 1 \\
\hline 2 & Tuberculous lymph nodes & 5 \\
\hline 3 & Lymphomatous nodes & 4 \\
\hline 4 & Metastatic nodes & 18 \\
\hline \multicolumn{2}{|c|}{ Total } & $\mathbf{2 8}$ \\
\hline \multicolumn{2}{|c|}{ Table 11: Lymph Nodal Masses on Ultrasound } \\
\hline
\end{tabular}

Out of 56 patients, 28 had lymph node enlargement. Most common type was metastatic nodes (18).

\begin{tabular}{|c|c|c|c|c|}
\hline $\begin{array}{l}\text { Sl. } \\
\text { No. }\end{array}$ & $\begin{array}{c}\text { US } \\
\text { Feature }\end{array}$ & & $\begin{array}{c}\text { Tuberculous } \\
\text { Nodes }\end{array}$ & $\begin{array}{l}\text { Metastatic } \\
\text { Nodes }\end{array}$ \\
\hline \multirow{2}{*}{1} & \multirow{2}{*}{ Shape } & round & 3 & 18 \\
\hline & & oval & 2 & - \\
\hline \multirow{2}{*}{2} & \multirow{2}{*}{$\begin{array}{c}\text { Soft tissue } \\
\text { oedema }\end{array}$} & present & 5 & - \\
\hline & & absent & - & 18 \\
\hline \multirow{2}{*}{3} & \multirow{2}{*}{$\begin{array}{l}\text { Intranodal } \\
\text { necrosis }\end{array}$} & present & 3 & 18 \\
\hline & & absent & 2 & - \\
\hline \multirow{2}{*}{4} & \multirow{2}{*}{ Matting } & present & 5 & - \\
\hline & & absent & - & 18 \\
\hline \multicolumn{5}{|c|}{$\begin{array}{c}\text { Table 12: Differentiation of Tuberculous and Metastatic } \\
\text { Nodes on Ultrasound }\end{array}$} \\
\hline
\end{tabular}

In our study, 18 patients of metastatic lymphadenopathy and 5 patient of tuberculous lymphadenopathy were noted. Metastatic lymph nodes ${ }^{10}$ had rounded shape and showed intranodal necrosis. In TB nodes, shape was not always rounded and intranodal necrosis ${ }^{11}$ was seen in 3 patients out of 5. Soft tissue oedema and matting was seen in all cases of TB.

\begin{tabular}{|c|c|c|c|c|c|c|}
\hline Sl. No. & Ultrasound Feature & & Nonspecific L.N. & Tuberculous L.N & Lymphomatous L.N & $\begin{array}{c}\text { Metastatic } \\
\text { L.N }\end{array}$ \\
\hline \multirow{3}{*}{1} & \multirow{3}{*}{ shape } & round & - & 3 & 4 & 18 \\
\hline & & & & & & \\
\hline & & oval & 1 & 2 & - & - \\
\hline \multirow{2}{*}{2} & \multirow{2}{*}{ echogenic hilum } & present & 1 & - & - & - \\
\hline & & absent & - & 5 & 4 & 18 \\
\hline \multirow{2}{*}{3} & \multirow{2}{*}{ calcification } & present & - & - & - & - \\
\hline & & absent & 1 & 5 & 4 & 18 \\
\hline \multirow{2}{*}{4} & \multirow{2}{*}{ necrosis } & present & - & 3 & - & 18 \\
\hline & & absent & 1 & 2 & 4 & - \\
\hline & Table 13: & trasound & atures of Metasta & c and Non-Metast & ic Lymph Nodes & \\
\hline
\end{tabular}

Nonspecific lymphadenopathy showed an echogenic hilum and an oval-shaped tuberculous nodes ${ }^{12,13}$ were rounded in 3 cases without echogenic hilum and no calcification. Lymphomatous nodes were rounded with no areas of necrosis/calcification/echogenic hilum. Metastatic nodes were rounded without echogenic hilum/calcification. They had areas of intranodal necrosis.14,15

\begin{tabular}{|c|c|c|}
\hline Sl. No. & Other Investigation & No. of Patients \\
\hline 1 & CT & 8 \\
\hline 2 & MRI & 2 \\
\hline \multicolumn{2}{|c|}{ Total } & 10 \\
\hline & Table 14: Other Investigations \\
\hline
\end{tabular}

Of the 8 pts. with CT scan of neck, 7 cases had metastases and showed features of rounded shape intranodal necrosis give the accurate level of lymphadenopathy, which helped in staging the disease. CT helped to localise the primary site of involvement in 5 patients. One case had branchial cleft cyst and CT showed a cystic lesion with good delineation of the extent of the lesion.

Of the 2 pts. with MRI, 1 pt. had cervical and mediastinal adenopathy, which were hypointense on T1WI and hyperintense on T2WI confirming that they are of tuberculous origin and also gave the extent of disease. Other pt. had lymphangioma and MRI was done to delineate the extent of disease.

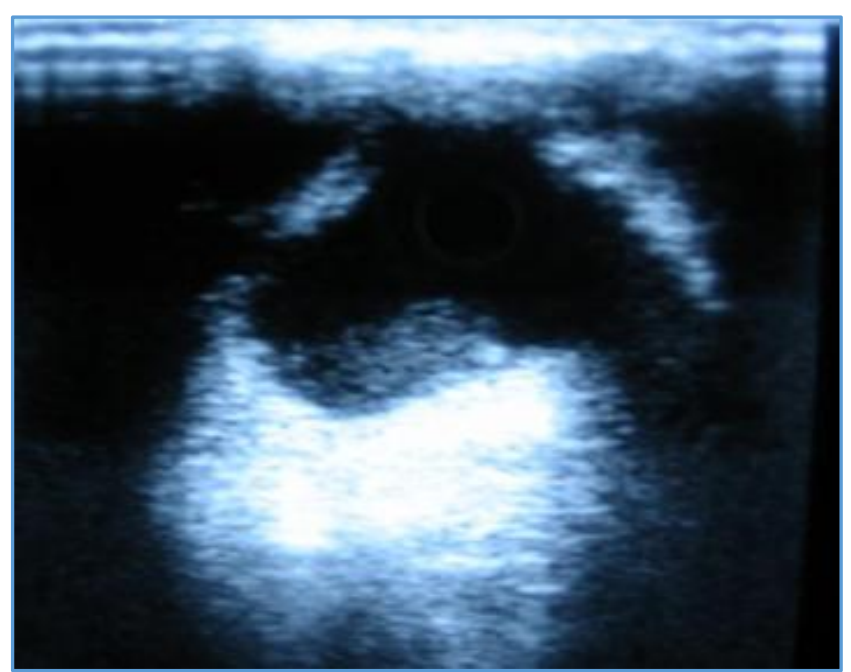

Fig. 1: US Neck Showing Cystic Lesion Noted in the Midline above Thyroid s/o Thyroglossal Duct Cyst 

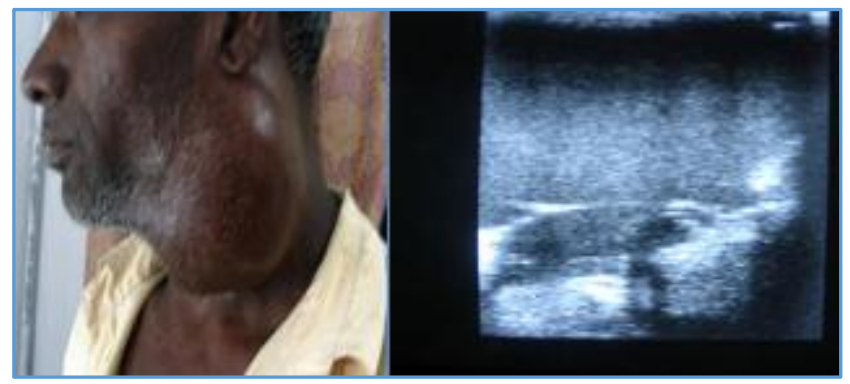

Fig. 2: Photograph of 45-Year-Old Male with Large swelling on Left Side of Neck and US Neck shows a Large Cystic Lesion Anterior to Carotid Vessels on the Left Side of Neck with Internal Echoes and Septations s/o II Branchial Cleft Cyst

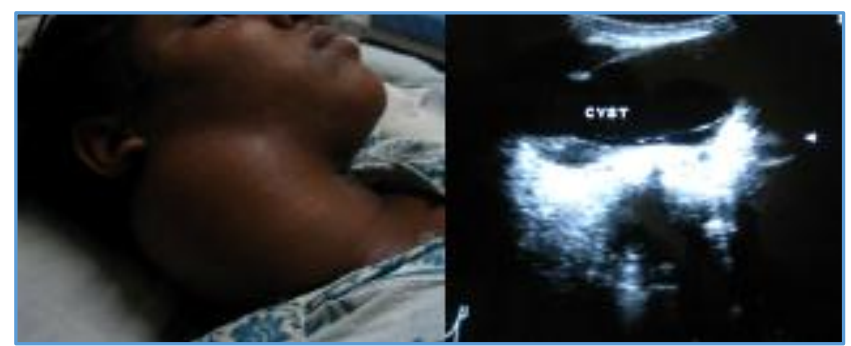

Fig. 3: A 19 Years Old Female with Swelling on Right Side of Neck and US of Neck Shows Cystic Lesion in the Rt. Cervical Region with Thin Internal Septations s/o Lymphangioma

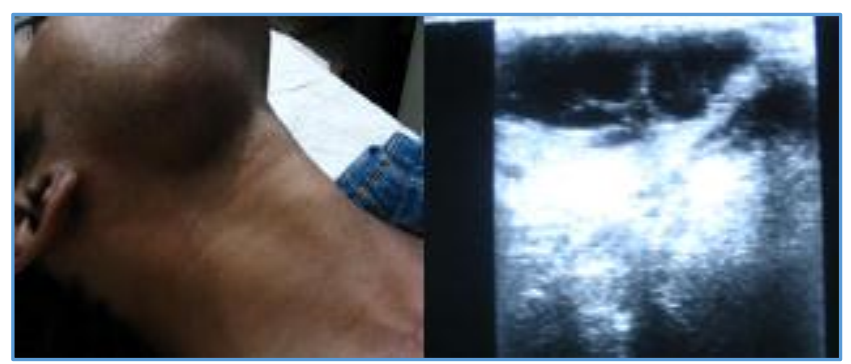

Fig. 4: A 35 Years Old Male Presented with Swelling in Rt. Submandibular Region 3 Weeks. US Neck shows

Hypoechoic Lesion of in Rt. Submandibular Triangle with Central Anechoic Areas. Submandibular Gland Normal s/o abscess

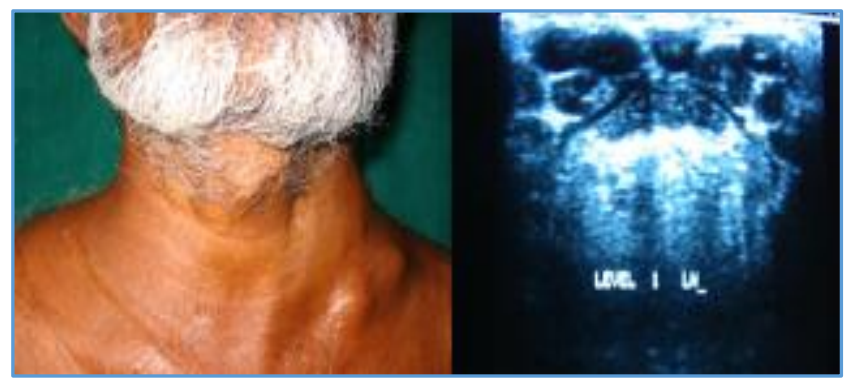

Fig. 5: A 52-Year-Old Male Presented with Generalised Lymphadenopathy, Hoarseness of Voice, Dysphagia, and US Neck showed Bilateral Multiple, Round Hypoechoic Masses of Varying Sizes with Positive Facet Sign s/o Bilateral Level 1 Lymphadenopathy s/o Lymphoma

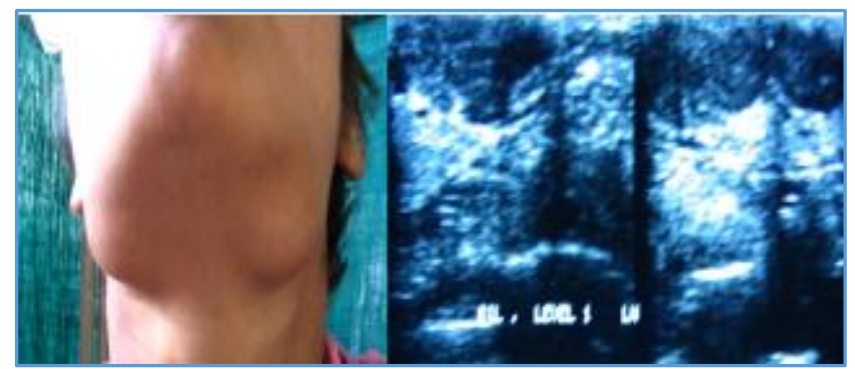

Fig. 6: A 22-Year-Old Female Presented with Mass in the Left Nasal Cavity and Swelling on Both Sides of Neck. US Neck Revealed Multiple, Bilateral, Round, Hypoechoic Mass Lesions in the Submandibular Region with Intranodal Necrosis s/o Bilateral Level 1 Metastatic

Lymphadenopathy and FNAC Reported as Small Round Cell Tumour

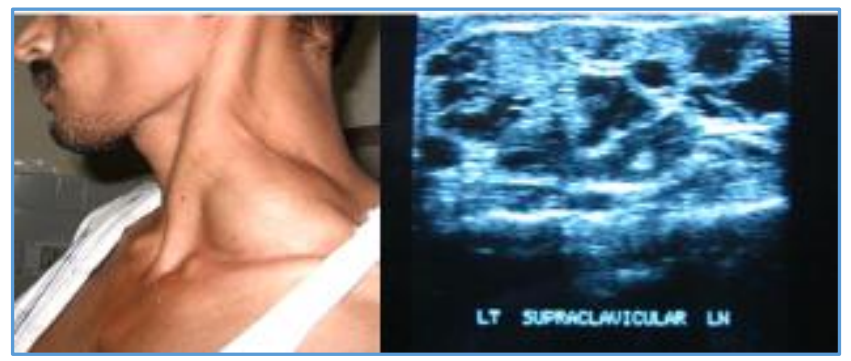

Fig. 7: A 30-Year-Old Male Presented with Swelling of Both Testes - 3 Months and Swelling on the Left Side of Neck - 2

Months .US of Neck Revealed Heterogeneous Mass with

Multiple Anechoic Areas in Left Supraclavicular Region s/o Metastatic Lymph Nodes

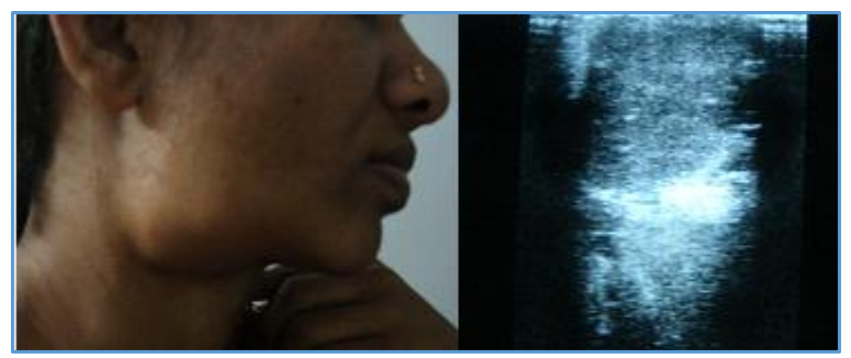

Fig. 8: A 29-Year-Old Female Presented with Swelling on Right of Neck-1 Year. US Neck shows Hypoechoic Solid Mass in the Right Submandibular Gland s/o Pleomorphic Adenoma of Right Submandibular Gland

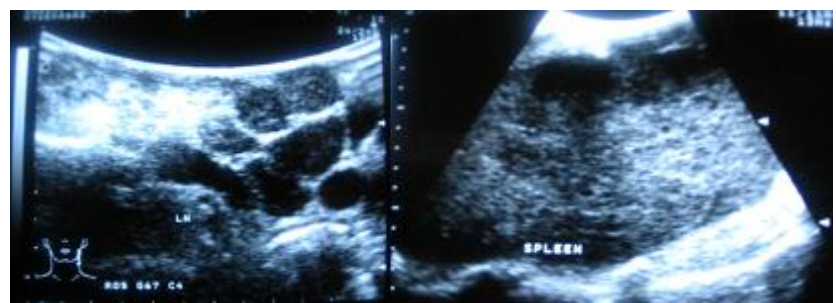

Fig. 9: A 60-Year-Old Male Presented with Swelling on Both Sides of Neck, Axillae, and Groin - 6 months. US Neck Revealed Multiple Rounded Hypoechoic Masses Involving the Entire Neck with Positive Facet Sign s/o Bilateral Level

1, 2, 3, 4, and 5 Lymphadenopathy s/o Lymphoma. US Abdomen shows Lymphomatous Involvement of Spleen.

\section{DISCUSSION}

Neck masses can be best diagnosed by anatomic localisation of the mass. This can be done by dividing the neck either into triangles or into spaces. Spaces of the neck is more useful for cross-sectional imaging. Neck masses can arise either from 
thyroid, parathyroid, or salivary glands or from other soft tissues, which can be cystic, solid, or mixed lesions. Thyroid masses account for majority of neck masses. However, in this study, we concentrated on extrathyroidal neck masses.

Radiological evaluation of neck masses can be done by $\mathrm{x}$ rays, ultrasound, CT, MRI, and scintigraphy. Among these investigations, radiograph is a basic investigation, which is advised in a patient with pressure effects to know the tracheal compression or displacement and also to look for calcification. Ultrasound can confirm the nature of lesion, 16 pickup, unsuspected, non-palpable lesions can diagnose whether the lesion is benign or malignant. ${ }^{17,18}$ It can also confirm the anatomic localisation of the mass and give a good diagnosis. Doppler evaluation can also be helpful in confirming the nature of the lesion. ${ }^{19}$ Ultrasound-guided FNAC can also be done. 20,21

In this study, 56 patients with neck masses within age group of 6 months- 67 yrs. were evaluated by ultrasound and correlation of ultrasound findings with FNAC was done. Ten patients were further evaluated with CT and MRI. Out of 56 pts., the most common age of presentation was $21-40 \mathrm{yrs}$. and 37 patients were male pts. All the 56 patients had neck masses and the common associated symptom was pressure effect due to the mass.

On ultrasound, the nature of lesions ranged from solid, cystic to mixed (25). Most of the cases were unilateral neck masses. Out of 56 cases, solitary neck masses (31) were predominant. In this study, the most common neck mass was metastatic lymphadenopathy. Out of 56, 18 pts. had metastases. The feature of metastatic lymphadenopathy on ultrasound are rounded-shaped sharp borders with central areas of necrosis.

Ying $M$ et al (1998) worked on cervical TB nodes and metastases in 47 pts. of TB and 27 cases of metastases and concluded that US features that helped to differentiate TB and metastases were shape, soft tissue oedema, intranodal necrosis, and matting. However, in this study, metastases had features of rounded shape and showed intranodal necrosis. TB nodes showed features of soft tissue oedema and matting in all 5 cases. Features like round shape and intranodal necrosis were seen in only 3 cases.

Pedrowesly et al (2005) studied the US features of lymph nodes in 112 pts. and concluded that oval shape and echogenic hilum are seen in benign lesions and presence of calcification and intranodal necrosis indicate metastases.

In this study, round shape and intranodal necrosis was seen in metastases whereas echogenic hilum and calcification was not seen in metastases. Next most common lesion was TB lymphadenopathy. US features of tuberculous lymph nodes were roundedness with areas of necrosis.

The margins of lesions were ill-defined and hazy. Associated soft tissue oedema is common.

All the 56 patients had FNAC/histopathological examination. In 55 patients, ultrasound findings correlated with FNAC/histopathological findings. One patient was diagnosed as lymphangioma and FNAC was inconclusive. The patient was not subjected to surgery and hence the followup is not available. 8 patients had further evaluation with CT and 2 patients had evaluation with MRI. Ultrasound evaluation of neck masses is a simple procedure with good diagnostic accuracy.

\section{Advantages of Ultrasound Evaluation of Neck Masses}

1. It is a quick and simple procedure.

2. It has a good diagnostic accuracy.

3. It helps to do followup examinations of neck masses.

4. Ultrasound-guided FNAC is useful in confirming the diagnosis.

Hence, we conclude that ultrasound with high resolution probe and FNAC is highly accurate and sufficient to diagnose and manage neck masses and suggest CT and MRI only in selected difficult cases for staging purpose.

\section{REFERENCES}

1. Harnsberger HR, Osborn AG. DD of head and neck masses based on their space of origin. 1. The suprahyoid part of the neck. AJR 1991;157(1):147-154.

2. Menwly JY, Lepori D, Theumann N, et al. Multimodality imaging evaluation of paediatric neck: techniques and spectrum of findings. Radiographics 2005;24(4):931948.

3. Som PM, Curtin HD, Mancuso AA. Imaging based nodal classification for evaluation of neck metastatic adenopathy. AJR 2000;174(3):837-844.

4. Kessler A, Rappaport Y, Blank A, et al. US diagnosis of cervical lymph node metastases from papillary carcinoma thyroid. Journal of Clinical Ultrasound 2003;31(1):21-25.

5. Torabi M, Aquino SL, Harisinghani MG. Current concepts in lymph node imaging. Journal of Nuclear Medicine 2004;45(9):1509-1518.

6. Ahuja AT, King AD, King $\mathrm{W}$, et al. Sonographic appearances of thyroglossal duct cysts in adults. AJNR 1999;20(4):579-582.

7. Ahuja AT, Kinga AD, Metreweli C. Second branchial cleft cyst: variability of sonographic appearances. AJNR 2000;21(2):315-319.

8. Marsot-Dupuch K. Congenital cervical anomalies. Journal of Radiology 1995;76(7):405-415.

9. Borecky N, Gudinchet F, Laurine R, et al. Role of US and MRI in the diagnosis of cervical thoracic lymphangiomas. Paediatric Radiology 1995;25(2):127-130.

10. Vassallo P, Wernecke K, Roos N, et al. Differentiation of benign from malignant superficial lymphadenopathy: role of high resolution US. Radiology 1992;183(1):215220.

11. Grainger RG, Allison DJ, Adam A, et al. Grainger and Allison's Diagnostic Radiology. $4^{\text {th }}$ edn. New York: Churchill Livingstone 2001.

12. Ahuja AT, Ying M. Sonographic evaluation of cervical lymph nodes. AJR 2005;184(5):1691-1699.

13. Etal YM, Ahuja AT, Evans R, et al. Cervical lymphadenopathy: sonographic differences between $\mathrm{TB}$ nodes and nodal metastases. Journal of Clinical Ultrasound 1998;26(8):383-389.

14. King AD, Tse GM, Ahuja AT, et al. Necrosis in metastatic nodes: diagnostic accuracy of CT, MR, and US. Radiology 2004;230(3):720-726.

15. Ying M, Ahuja A. Sonography of neck lymph nodes. Part I: normal lymph nodes. Clinical Radiology 2003;58(5):351358.

16. Glastonburg CM. Thyroglossal duct cysts in adults. AJNR 2000;21(4):770-774. 
17. Sumi M, Ohki M, Nakamura T. Comparison of sonography and CT for differentiating benign from malignant cervical lymph nodes in patients with squamous cell carcinoma of the head and neck. AJR 2001;176(4):1019-1024.

18. Ahuja AT. Cervical lymphadenopathy evaluation by US, Doppler, and FNAC. Invest Radiology 2002;333-342.

19. Brinc Z, Hebranq A. Evaluation of cervical lymphadenopathy by Doppler. Neuroradiology 2003;13(1):175-180.
20. Sack MJ, Weber RS, Weinstein GS, et al. Diagnostic utility of image-guided FNA in head and neck. Archives of Otolaryngology-Head and Neck Surgery 1998;124(10): 1155-1161.

21. Pedrowesly. US features of lymph nodes. Journal of Ultrasound Medicine 2005;24:135-1389. 